\title{
N. Meihuizen
}

\section{Bosman and Self-Conscious Fiction}

\begin{abstract}
Bosman, in a number of ways, underlines his fascination with his medium. In this article, an attempt is made to indicate some of the ways in which he does this. Particular attention is paid to Bosman's use of commentary, his own self-conscious reflections on the text before the reader. Using two stories, "Unto Dust", and "Old Transvaal Story", I present the ways in which Bosman's self-consciousness manifests itself in his art. If he is so adept at undermining illusion, what yet entertains us in the most self-conscious of his texts? It is argued that his fascination with his medium is buttressed by his ability to delude us, which displaces our reliance on illusion.
\end{abstract}

\section{Introduction}

Bosman often comments upon his art in the course of his stories. These comments reinforce our awareness of the illusory nature of art, and yet Bosman is still able to hold us in his storyteller's grip. Why should this be so? The matter is related to his sheer craftsmanship, noted, for example by Hennie Aucamp (Aucamp, 1978:83, 90). But literary craftsmanship which distances itself from illusion must find another focus. I would suggest, as I hope this article makes clear, that through his comments and other devices, Bosman makes illusion subordinate to delusion, the latter as entertaining in its way as the former.

Stephen Gray elegantly elaborates on the aspect of commentary in Bosman's writings: "His on-going commentary on the practice of fiction intrudes quite frequently as you read along, as he explains himself, backtracks, apologizes, insists that it is only a trick after all. Often he actually explains the trick to you, only to pull another one later. He was as interested in his medium as he ever was in the Marico ..." (Gray in Bosman, 1980:14). The emphasis on medium is also apparent in the typical features of a Bosman short story: exaggeration, bogus naivete, malapropisms, misquotations, incongruities and circumlocutions. Alfred Appel, in his foreword to Lolita, writes of "involuted" work, or work which "turns in upon itself, is self-referential, conscious of its status as fiction ...". Aspects of such work are detected by Appel in Nabokov, and might as easily be detected in Bosman: parody, patterning, the work-within-the-work and the authorial voice (Appel in Nabokov, 1970: xxii-xxxi).

\section{Theoretical background}

Relatively early in the Anglo-Saxon world Appel was expressing a theoretical interest in self-conscious literature, an interest since more thoroughly formulated in works such as 
Linda Hutcheon's Narcissistic Narrative: The Metafictional Paradox (1984) and Patricia Waugh's Metafiction: The Theory and Practice of Self-Conscious Fiction (1984). Howard Felperin, in Beyond Deconstruction: The Uses and Abuses of Literary Theory (1986), suggests that such theoretical works are part of a present historical moment in a long tradition:

The recent paradigm-shift toward theory, which has enabled such [self-conscious] texts to be read as never before, and writerly modernity to be radically backdated, may itself be only the latest phase of that larger change in the status of writing which enabled such self-critical and self-destabilizing texts to be produced in the first place, the academic institutionalization of a textual self-consciousness long since in train. (Felperin, 1986:200.)

Felperin (1986:200) "backdate[s]" "modernity" in order to include such works as Don Quixote, The Tempest, and Tristram Shandy, the potential of the last-named work for "laying bare" its own devices long since recognized by Viktor Shklovsky (Selden,1986: 11). But as Waugh hints, the practice of self-consciousness might be older than the novel itself (1984: 5). Indeed, Roland Barthes, in his famous essay of 1968, "The Death of the Author", implies that since its emergence, writing has underlined the textuality of the text:

As soon as a fact is namated no longer with a view to acting directly on reality but intransitively, that is to say, finally outside of any function other than that of the very practice of the symbol itself, this disconnection occurs, the voice loses its origin, the author enters into his own death, writing begins. (Barthes in Lodge, 1988:168.)

But if all fiction is inherently self-conscious, it is yet possible and necessary to categorize different types of self-consciousness in order to draw very obvious distinctions. For example, while "[o]ver the past twenty years, novelists have tended to become much more aware of the theoretical issues involved in constructing fictions" (Waugh, 1984: 2), this is certainly not true of Bosman. He is not concerned with "explor[ing] a theory of fiction through the practice of writing fiction" (ibid). One feels, as remarked earlier, that his principal concern is to entertain. Peter Hutchinson, in Games Author's Play (1983), indicates that entertainment is one of the basic attributes of literary play (Hutchinson, 1983:13). This is not to say that Bosman doesn't share certain other attributes with contemporary writers of metafiction ("... fictional writing which self-consciously and systematically draws attention to its status as an artifact in order to pose questions about the relationship between fiction and reality" (Waugh,1984:2). We can extrapolate from Waugh's list of the fundamental attributes of metafiction attributes which clearly apply to Bosman, as a glance back at Appel's list will help corroborate:

[A] celebration of the power of the creative imagination together with an uncertainty about the validity of its representations; an extreme sclf-consciousness about language, literary form and the act of writing fictions; a pervasive insecurity about the relationship of fiction to rcality; a parodic, playful, excessive or deceptivcly naive stylc of writing (ibid).

But uncertainty and insecurity are not characteristic Bosman traits. I am implying that Waugh's list indicates a distinction in the production of self-conscious literature, reflecting to an extent Roger Fowler's distinction between the intense self-consciousness of postWorld War-II literature (aided by the writers' growing awareness of theoretical issues) and "modernist self-consciousness" (Fowler, 1987:96), which would include Bosman's work. 
Self-consciousness is not new in the eighties in South Africa, where young Afrikaans writers (such as Koos Prinsloo, in Jonkmanskas and Die hemel help ons) exploit to the full techniques which underline the nature of the medium (Prinsloo, 1982, 1988). And, to remain with Prinsloo, the commendable dissertation on Jonkmanskas by A.W.Botha (1987) is representative evidence that South Africa is not lagging behind in its appreciation and understanding of self-conscious techniques in literature. Present local involvement with such techniques however focuses on the intense variety of self-consciousness; the modernist selfconsciousness of Bosman still deserves attention, as, apart from its own intrinsic value, it helps demonstrate a continuity in the development of literary self-consciousness in South Africa.

\section{Bosman and self-conscious fiction: a general overview}

What is intriguing about Bosman is the garb in which he clothes his materials. Marico farmers are, at first sight, even less likely characters in contemporary fiction than Umberto Eco's medieval monks. The South African bushveld was indeed virgin territory for one establishing twentieth century literary techniques. But although Bosman inaugurates, as it were, this century in the bushveld, he never swerves from being true to the ingrained nature of the bushveld. Indeed, aspects of his self-conscious art (for example, the disclosure of illusion, or the explanation of the "trick", as Gray puts it) chime perfectly with the cunning playfulness of the traditional "fireside" storyteller.

Gray gives a useful concise breakdown of the pattern of a Bosman short story, which we might apply to actual examples in attempting to highlight Bosman the self-conscious artificer. He writes that, "[t]he pattern in each of Bosman's stories is one of a theme with variations, around which all the material is shaped". "With the resolution", notes Gray, "all those different views [presented by the variations] are brought into focus on the original theme, so that it leaps into clarity". He further notes that "a small and unexpected detail, mentioned casually in the introductory section", often turns out to be of prime importance in illuminating the whole", and he refers to "the recurring yellow dog in 'Unto Dust' as a 'neat example"' (Gray in Bosman, 1980:15-16).

\section{"Unto Dust"}

"Unto Dust" warrants closer observation. The general theme of the story is death, or to be more particular, the prejudices we have regarding the dead. This is apparent in the opening sentence, which indicates the differing attitudes people have towards those who die young and those who die old: "I have noticed that when a young man or woman dies, people get the feeling that there is something beautiful and touching in the event, and that it is different from the death of an old person" (Bosman, 1983:13). The bare fact of death is also reflected on in this paragraph, although in a humorous way, through "the crude questions that a couple of men in plain clothes from the land-drost's office are asking about cattle-dip". The crude questions take the edge off what may be romantic about a young girl's death, and expose a more stark conception of death as the leveller, the second important theme in the story. The second and third paragraphs offer a corrective to the conventional attitudes towards death displayed in the first paragraph. As romantic as the 
young girl's death seems, it is blighted by suspicion. As unromantic as the old man's death seems, it is yet touched by the beauty of a "hallowed sort of calm", despite the presence of cloven-hooved "angels", which we might see as acting in concert with the notion of death the leveller (Bosman, 1983:13). Thus these paragraphs on the one hand qualify our prejudiced perceptions regarding the dead, but on the other also affirm that death is indeed a leveller.

The remainder of the story plays with these two themes, prejudices about the dead and death the leveller, in the controlled manner of a card game (characterized by concealment and bluff), indicating a strong authorial presence. For example, the fourth paragraph deals with prejudices, which now have racial overtones, an elaboration on or variation of the original theme. Mention is made of special "civilized Christian" graves for "white people" as compared to a "Bushman" buried "with a clay-pot, and things" (Bosman, 1983:14). In a sequence mirroring the earlier thematic one, Bosman returns to the idea of death the leveller in the fifth paragraph, but also provides a variation on that theme (as he does with the theme of prejudice in the fourth paragraph). The variation takes the form of a vigorous denial that death is a leveller. By this point we have reached quite a complex stage thematically, where Bosman, tacitly setting himself up as the reader's opponent, plays with ideas, suggests things, but never reveals his hand. In short, he sets out to delude us, and we participate in the game with enjoyment.

The denial that death is the leveller is also in time repudiated, and this fact is hinted to us soon, although the implicit repudiation which now holds us in suspense is never made explicit until the end of the story. Stoffel Oosthuizen's disbelief regarding death the leveller is illustrated by his story of "an incident that took place in a bygone Transvaal Kafir War" (p. 14). But the narrator comments in a perturbed way, "I don't know whether he told the story incorrectly, or whether it was just that kind of story, but, by the time he had finished, all my uncertainties had, I discovered, come back to me" (p. 14). On what are the narrator's "uncertainties" based is a question that stays with us throughout the remainder of the story. Alerted in this way, we are made party to his uncertainty without yet knowing why. We are actually caught up in a "trick". Being made party to the unintentional irony of the second narrator, Stoffel Oosthuizen, although the ironic situation has not yet been revealed, we are at the mercy of the writer. But which theme is being brought into question by the irony, prejudice regarding death or the notion of death the leveller? The first five paragraphs suggest that both themes are connected; thus we have a fairly good idea of the nature of the irony, even at this stage. In our anticipation we are further made party to the "trick" of ironic reversal yet to be revealed.

Stoffel Oosthuizen's story concerns a Boer killed by a Black who has his yellow dog with him. In hasty retreat, Oosthuizen yet manages to shoot and kill the Black. Later, the other Boers try to find the remains of the dead Boer, Hans Welman, but his remains are indistinguishable from those of the Black who was shot next to him. Again mention is made of the yellow dog, faithfully guarding its master's remains. Because the two corpses are indistinguishable, the Boers carefully pick out what they hope to be Welman's remains and take them home for burial in a hallowed Christian grave-yard. As Stoffel Oosthuizen's point in telling this story is to deny the contention that death is the great leveller, we are left wondering at the significance of a clear illustration of death as the leveller:

... no matter what the difference in the colour of their skin had been, it was impossible to say that the kafir's bones were less white than Hans Welman's (Bosman, 1983:16). 
But we are being deluded. The resentment of the Boers, their tacit and bitter awareness that death is a leveller (which gains in strength through being repressed), has the power to conceal, at this crucial stage in the story, Bosman's final hand. Even if according to the apparently incontrovertible evidence of our senses (dramatized in the resentment of the Boers), death is the leveller, this is not necessarily so. The yellow dog, ever faithful to its master, is seen beside "Hans Welman's" grave. Thus, in a completely unexpected manner, Stoffel Oosthuizen's denial that death is the great leveller, although recently subverted, is here proved true. The principal narrator, then, is uncomfortably placed in whichever direction he turns, and herein lies the irony behind Oosthuizen's originally "comforting" words. Oosthuizen's account first brings the realization that contrary to the principal narrator's hopes death is the great leveller. But then shortly afterwards the principal narrator realizes that this need not, in fact, be the case. He learns this, though, through circumstances which he cannot accept with any peace of mind. This convoluted irony is anything but predictable, and we have been deluded, again, into attempting to predict it.

In this little story, then, Bosman plays a more complex game than might at first appear. He presents two themes - the prejudices people have about the dead, and death the leveller and variations on these themes. One of the variations is that just as the old might die with more grace than the young, despite our prejudice to the contrary, so might a Black be better remembered than a Boer. The other theme (death doesn't distinguish between people), has as a variation its antithesis - death does indeed distinguish between people. The idea of death the leveller, an obvious, stock one, is qualified by a vigorous denial, which is first shown to be inconsequential; perhaps the obvious will triumph after all. But this perception is in turn subverted by a very moving reversal and the ironic effect of the reversal is to leave a sense of discomfort where there should have been comfort; the world order has been inverted, nothing remains sacred. As Gray (in Bosman, 1980:16) has noted, the small, unexpected detail, the yellow dog, is that which causes this reversal and finally brings all the threads of the story together in an unexpected and moving way, despite the fact that we have (although not with our original confidence perhaps), anticipated the general outcome. The entire presentation of the yellow dog has been a form of textual play. The dog has been dangled before our noses, as it were, at various points in the story, without our understanding its significance until the end. It has been used as a device to draw our attention in an almost unnoticed way. Then when Bosman has played himself into a corner (a brief paragraph remains for him to subvert an apparently overwhelming conclusion) this insignificant card is seen to be the ace up his sleeve, the concluding detail in a delusive strategy.

\section{"Old Transvaal Story"}

A story which emphasises self-conscious authorial intervention, in a far more explicit manner, is "Old Transvaal Story" from the collection Unto Dust. With a reference to Scully's "Ukushwama" (1984:38) in a foregrounded position in its first sentence, a device which immediately draws attention to the medium (Bosman, 1983:90), it is a stock Transvaal murder story, apparently, employing an old formula. Indeed, its elements (the murder and burial under the floor, and then the arrival of jovial company) make up, Bosman feels, the only Transvaal murder story. (He himself has employed the formula before, in "The Gramophone", from Mafeking Road (Bosman, 1984:99). In short, he does much to convince us of the transparency and threadbare nature of such tales. Exposing thus the shortcomings of the medium, Bosman engages in a very sophisticated form of self-con- 
scious textual play. He denies the validity of his materials, yet must make good use of those same materials. In a sense, he is undermining his position and affirming his faith in it at the same time. The resulting tension contributes to the appeal of the story. We become suspicious as elements recently derided enter the story, yet knowing Bosman, we can never be sure whether or not our suspicions are justified. On our guard, we are actively involved in the success of the trick, just as a field full of defensive players is necessary to complete the breathtaking effect of one player on the offensive darting through the entire field.

In the "Old Transvaal Story" the subject is ostensibly a discussion about formulaic stories, their technique and content. The first section of "Old Transvaal Story" tells of the formulaic ghost story. Such a story contains certain essential features, and Bosman's breakdown of the features suggests a rudimentary form of the structural analysis undertaken by Vladimir Propp, in Morphology of the Folktale (1979:18-24). If Propp indicates that certain elements of a story might be varied without altering the essential plot (Culler, 1980:207), so does Bosman. But Bosman is not intent on isolating "roles" or the "functions of dramatis personae" (Propp, 1979:25ff.), his aim, at this stage, is the "undermining of familiar conventions" (Waugh, 1984:12):

A solitary traveller on horseback enquires his way at a farmhouse after dark.

"That means you'll be going through the poort" (or the kloof or the drift, as the casc may be) "at full moon," the farmer says to the traveller. "Well, no man has ever been able to ride his horse through that poort at night when the moon is full." (Bosman, 1983:90.)

The "authorial voice" in brackets undermines the illusion, as does the bare summary of events which follows. But even the bare summary, interestingly, is able to hold our attention, reflecting both Bosman's skill and the fact, as he acknowledges, that "this is a good story". The value of the story is also borne out by Scully's adaptation of the formula in "Ukushwama", so laid bare by Bosman that we cannot help but smile. For example, Numjala, headman of the Bacas, tells the narrator: "Unless your horse leads well, you will never get him past the Ghoda to-night, this being the night of the New Moon. You will certainly never ride him past" (Scully, 1984:39). Yet even as we smile, we become absorbed. Bosman must further undermine the formula, then, by pointing out that he has heard dozens such stories with only slight variations, to the extent where he has become blase about them. His boredom with them finds an outlet in a subversive humorous detonation, which spoils the story from the outset:

... I've got somewhat blasé about the Transvaal's only ghost.

The result is that, nowadays when a man says - lowering his voice and trying to make his tones sound sepulchral, "And so Oom Hannes Blignaut said to me that I would not be able to ride my horse through that poort in the full moon," I short-circuit him by asking, "But why didn't you go on a pushbike, instead?"

I have not, to date, found an answer to that onc. (Bosman, 1983:91.)

Thus the story-teller himself exposes the tricks of the trade and ridicules them. But he also leads us a merry dance, even at this stage, because we now learn that the "Old Transvaal Story" of the title isn't, in fact, a ghost story, but a murder story. Or is it? For a few pages later Bosman seems to settle down to tell us a love story.

In the meantime, the murder story that he outlines to us is seen to contain the same formula used in "The Gramophone": 
The man has murdered his wife. - Good. - He has buried her under the floor of the voorkamer. Right. - He proceeds to smooth over the broken portion of the floor with clay and moist cow-dung. Yes, excellent. All that seems straightforward enough. (Bosman, 1983:91)

He then describes the twist in the story, the friends arriving that very night to throw a surprise party. In "The Gramophone" Oom Schalk Lourens' arrival had supplied this twist, and so Bosman clearly seems to be explaining his own trick to us in terms of a predetermined formula. The implication is that once we know the formula we can't be tricked. Secrets are being revealed to us, we are in the author's confidence, and our complacent sense of acceptance is being played upon or developed.

At this point we are told of the "hundreds" of Transvaal love stories, "all opulently different". Apparently, then, the love stories are completely unlike the ghost and murder stories as far as variety goes. Indeed, Bosman, refuting the value in this case of what might almost be seen as rigorous Proppian analysis (had he known about it), writes:

One must be careful about classifying a love story, tabulating and cataloguing it as belonging to a certain sub-section of a particular group - indexing it and labelling it as conforming, in respect of characters and plot and incident, to a well-known and clearly recognized pattern. (Bosman, 1983:93)

This is another trick, however, played at the time when we least expect it, the time when Bosman is explaining the conventional tricks. He then refers to a specific love story, stating how difficult it is to categorize it. The story seems conventional enough at first - two young people appear to be in love and are to be married. A third figure is introduced, Rooi Jan Venter, who plays, apparently, an important part in the girl's life - she "keeps mentioning his name"; and only after we hear it do we learn of her "affection" for her bridegroom-tobe but at the same time her lack of passion for him. The implication is that the other man does stir passion in her. But more is left unsaid than said.

As we approach the denouement, the couple are married. The narrator continues to imply matters rather than state them explicitly:
And then events slid into that afternoon on which Gideon Welman was working very fast, and in a half-daze. He had the queer fecling that he was living in another life, going through a thing that had happened before, to somebody else, long ago. It was quite dark by the time a knock came at the door.
And when he got up from the floor quickly, dusting his knees, Gideon Welman knew what the old Transvaal story was, into whose pattern his own story had now fitted, also. For the door of the voorkamer opence. And out of the night came the laughter of girls. And Rooi Jan Venter and another young man entered the voorkamer, carrying bottles. (Bosman, 1983:94)

We have been deluded, perhaps, by the categorizing mind, for even although Bosman discussed, in turn, the ghost story, the murder story and the love story, centring finally on the love story, there is no reason on earth why a love story should not also be a murder story. The merging of genres is signalled by the appearance of Rooi Jan Venter, a catalyst figure on whose account a love story is transformed into a murder story, apart from the fact that he features at crucial moments in both.

\section{Bosman's significance in contemporary South African fiction}

Thus, in Bosman, even the most self-conscious of texts is able to entertain, if not through illusion then certainly through delusion. The story-teller's art, in becoming its own subject, 
reaches a McLuhanesque condition where the medium is the message (or the message is the medium), but where the message/medium relies, as in the most traditional of texts, on the story-teller's skill. I come back, then, to an earlier perception: inherent in the skill and cunning of an Oom Schalk Lourens are, mutatis mutandis, the techniques and devices apparent in the most sophisticated of self-conscious texts. I think the point is well understood by Aucamp, for instance, who in "Vir Vier Stemme" (in Smuts, 1989:114-31) combines a distinctively Bosmanesque narrative technique (which evokes, for example, the ambience of the fire-side tale and Bosman himself, thus highlighting the element of artifice in the story) with a set of multi-faceted perceptions of the type one finds in Lawrence Durrell's Alexandria Quartet (1970). Durrell, employing a mode of illusion, nevertheless relies a great deal upon his ability to delude, which only becomes apparent as we progress through the many perspectives offered by the Quartet. Through his use of differing perspectives, Aucamp seeks to cast more and more light upon the central incident of his story, the sad death of an ironically misused homosexual. To do this, like Durrell, he has to shatter our illusion of chronological sequence, and open up his initial story to events covering the same span of time, but previously undisclosed. They become, as it were, a commentary on the original text, differing only in degree and not in kind from Bosman's textually placed commentaries on his art (which must include his own "central" text or story as distinct from his commentaries). The link between Bosman and Aucamp indicates the continuity of a tradition of self-consciousness in South African writing - Aucamp, in a sense, bridges the gap between the "modernist" self-consciousness of Bosman and the "intense" self-consciousness of Prinsloo. Central in this way, Bosman's story-telling techniques surely deserve closer scrutiny in studies of contemporary South African fiction.

\section{Bibliography}

Aucamp, H. 1978. Kon voor lank: opstelle oor kortprosatekste. Kaapstad: Tafelberg. Bosman, H.C. 1980. Selected Stories. Gray, S. (cd.) Cape Town/Pretoria: Human \& Rousseau. Bosman, H.C. 1983. Unto Dust. Cape Town/Pretoria: Human \& Rousseau.

Bosman, H.C. 1984. Mafeking Road. Cape Town/Pretoria: Human \& Rousseau.

Botha, A.W. 1987. 'n Onderskeiding tussen lee en betekenisdraende tekens in die literêre kommunikasieproses. Geillustreer aan die hand van "Die Jonkmanskas" van Koos Prinsloo. Bloem fontein (Thesis (MA) - University of the Orange Free State.)

Culler, J. 1980. Structuralist Poetics: Stnucturalism, Linguistics and the Study of Literature. London: Routledge \& Kegan Paul.

Durrell, L. 1970. The Alexandria Quartet. London: Faber and Faber.

Felperin, H. 1986. Beyond Deconstruction: The Uses and Abuses of Literary Theory. Oxford: Clarendon Press.

Fowler, R. 1987. A Dictionary of Modem Critical Terms. London: Routledge \& Kegan Paul.

Hutcheon, L. 1984. Nancissistic Narrative: The Mctajictional Paradox. New York: Methuen.

Hutchinson, P. 1983. Games Author Play. London: Methuen.

Lodge, D. (ed.) 1988. Modem Criticism and Theory: A Reader. London: Longmans.

Nabokov, V. 1970. Lolita. Appel, A. (ed.) New York: McGraw Hill.

Prinsloo, K. 1982. Jonkmanskas. Kaapstad: Tafelberg.

Prinsloo, K. 1988. Die hemel help ons. Epping: Taurus.

Propp, V. 1979. Morphology of the Folktale. Scott, L. (trans.). Austin: University of Texas Press.

Scully, W.C. 1984. Transkei Srories. Marquard, J. (ed.) Cape Town: David Philip.

Selden, R. 1986. A Reader's Guide to Coniemporary Literary Theory. Brighton: The Harvester Press.

Smuts, J.P. (ed.) 1989. Koker: Konprosatekste sedert Sestig. Kaapstad: Tafelberg.

Waugh, P. 1984. Metafiction: The Theory and Practice of Self-Conscious Fiction. London: Methuen

University of Zululand 